\title{
RETOS Y ALCANCES DE LOS MECANISMOS DE SEGUIMIENTO A LAS DECISIONES PROFERIDAS EN LOS PROCESOS DE ACCIÓN POPULAR
}

\author{
Anamaría Bonilla Prieto \\ Recibido: Marzo 17 de 2017 \\ RESUMEN \\ Aprobado: Mayo 2 de 2017
}

Este artículo presenta una recopilación de los mecanismos que se encuentran al alcance de los jueces a la hora de hacer seguimiento a las órdenes proferidas dentro del marco de los procesos de acción popular. Ello resulta fundamental en un contexto en el que se presentan serias dificultades en la etapa de ejecución de los fallos de acción popular que ponen en riesgo su finalidad última de lograr la defensa real y efectiva del interés público. Este escrito busca hacer una evaluación crítica enfocada en las bondades y los retos que suponen dichos mecanismos en su implementación cotidiana con el fin de realizar un diagnóstico general de la situación actual y proponer alternativas que permitan reforzar y ampliar las herramientas existentes a futuro.

Palabras clave: Mecanismos de seguimiento, Acciones Populares, Derechos Colectivos, Comité de Verificación y Seguimiento.

\section{CHALLENGES AND COVERAGE OF MECHANISMS OF EXECUTION FOR DECISIONS MADE IN THE PROCESSES OF GROUP AND COLLECTIVE RIGHTS}

\begin{abstract}
This article presents a compilation of the mechanisms that the judges have at the time of following the orders issued within the framework of the popular action processes. This is fundamental in a context in which

* Estudiante de décimo semestre de Jurisprudencia de la Universidad del Rosario. Este artículo es producto del proyecto de investigación sobre litigio estructural en América Latina desarrollado en el marco del convenio de cooperación firmado entre la Universidad del Rosario, el Ministerio Público Fiscal y la Universidad de Buenos Aires. Correo electrónico: anabonillaprieto@gmail.com.
\end{abstract}


there are serious difficulties in the execution stage of popular action failures that jeopardize their ultimate goal of achieving real and effective defense of the public interest. This text aims to make a critical evaluation focused on the benefits and challenges of these mechanisms in their daily implementation in order to make a general diagnosis of the current situation and propose alternatives to strengthen and expand existing tools in the future.

Key words: Mechanisms of execution, Popular Actions, Group and Collective Rights, Verification and follow-up committee.

\section{DESAFIOS E ALCANCES DOS MECANISMOS DE SEGUIMENTO ÀS DECISÕES PROFERIDAS NOS PROCESSOS DE AÇÃO POPULAR}

\section{RESUMO}

Este artigo apresenta uma compilação dos mecanismos que estão disponíveis para os juízes na hora de fazer acompanhamento às ordens proferidas no âmbito de processos de ação popular. Isto é essencial em um contexto em que se apresentam sérias dificuldades na fase de execução das decisões de ação popular ameaçando sua finalidade para alcançar defesa real e efetiva do interesse público. Este artigo procura fazer uma avaliação crítica focalizada nos benefícios e os desafios que supõem esses mecanismos na implementação cotidiana, a fim de realizar um amplo diagnóstico da situação atual e propor alternativas para fortalecer e expandir as ferramentas existentes para o futuro.

Palavras-chave: Mecanismos de acompanhamento, Ações populares, direitos coletivos, Comitê de verificação e acompanhamento.

\section{INTRODUCCIÓN}

En sociedades caracterizadas por la fragmentación y la desigualdad, se ha dado tránsito a un modelo que pone inevitablemente la parte dogmática de la constitución en un rango supremo y que genera un creciente activismo judicial. Al tratarse de un escenario que supone la presencia de intereses enfrentados y que tiene como fin último la garantía de derechos humanos, el papel del juez debe evaluarse bajo una luz distinta. Lejos de mediar de forma neutra, el juez puede elegir interpretaciones alternativas de acuerdo con el resultado que considere más justo(Kennedy, 1999). 
En el caso de las acciones populares, la normatividad dispuesta buscó atender a la complejidad de las problemáticas y a la importancia de los derechos en juego. Por ello, se caracteriza por la búsqueda de informalidad y sencillez en los procedimientos, la accesibilidad de la acción al ciudadano del común y la consagración de herramientas amplias que le permitan al juez de conocimiento actuar e innovar con el fin último de lograr la protección de los derechos colectivos. Así, dentro del proceso se han concedido amplísimos y flexibles poderes al juez que le otorgan el rol de actor preponderante y que hacen que el cumplimiento de sus fallos dependa en gran medida del rol pasivo o activo por el que opte durante la etapa de ejecución.

Este artículo pretende realizar un análisis práctico de los mecanismos que han sido otorgados a los jueces para lograr un seguimiento y cumplimiento adecuado de las órdenes impartidas en el proceso de acción popular. Para ello, se realizará primero un recuento de las herramientas que ha dispuesto la ley 472 de 1998. Seguidamente, se llevará a cabo un análisis crítico de las bondades y dificultades que se encuentran presentes en la implementación práctica de los mecanismos descritos. Para ello, se ilustrarán las problemáticas que se han suscitado en la práctica, se propondrán alternativas para hacer frente a los vacíos metodológicos encontrados y se harán recomendaciones con el fin de reforzar las figuras existentes.

\section{MECANISMOS DE SEGUIMIENTO ESTABLECIDOS EN LA LEY 472 DE 1998}

\subsection{Los amplios poderes del juez, la figura del Auditor y el Comité de Verificación}

La ley 472 (1998), buscó dotar al juez de acción popular de potestades que le permitiesen asegurar el cumplimiento de sus decisiones dentro del proceso. Así, se consagran como mecanismos de control para el seguimiento de la sentencia aprobatoria de pacto de cumplimiento y de la sentencia que pone fin al proceso: las amplias facultades que permanecen en cabeza del juez una vez culminado el proceso, la figura del auditor y la conformación discrecional del Comité de Verificación como herramientas de soporte (Consejo de Estado, 2003).

Con respecto al cumplimiento de la sentencia aprobatoria de pacto de cumplimiento, el artículo 27 de la Ley 472 (1998) establece que "el juez conservará la competencia para su ejecución y podrá designar a una persona natural o jurídica como auditor que vigile y asegure el 
cumplimiento de la fórmula de solución del conflicto" (negrilla fuera del texto original). Con ello, deja claro que la competencia del juez se extenderá más allá de la finalización anticipada del proceso con el único fin de buscar la ejecución de lo pactado y dispone como mecanismo específico del que el juez podrá hacer uso a la figura del auditor.

En cuanto a las facultades del juez en materia del cumplimiento de la sentencia de mérito, el artículo 34 dispuso a su vez que el juez conservará, dentro del plazo que señale en la sentencia para el cumplimiento de la providencia, "la competencia para tomar las medidas necesarias para la ejecución de la sentencia [...] y podrá conformar un comité para la verificación del cumplimiento de la sentencia en el cual participarán además del juez, las partes, la entidad pública encargada de velar por el derecho o interés colectivo, el Ministerio Público y una organización no gubernamental con actividades en el objeto del fallo"(negrilla fuera del texto original) (Ley 472, 1998). El artículo, en modo similar al anterior, perfila dos funciones diferenciadas: de una parte, reitera la que permanece en cabeza del juez para realizar todo aquello que resulte necesario para la protección efectiva del derecho colectivo, de otra, la que corresponde a título de colaboración y apoyo, al Comité de Verificación (Consejo de Estado, 2003).

Como se expondrá más adelante, en la práctica los jueces han sido en su mayoría tímidos y poco creativos en el ejercicio de sus poderes para asegurar el cumplimiento de las órdenes impartidas y han optado en su mayoría por hacer uso de la figura del Comité de Verificación para realizar el seguimiento. Este se ha convertido en la opción principal y necesaria para asegurar la ejecución efectiva de las órdenes proferidas por el juez, utilizándose indiscriminadamente para el seguimiento de la sentencia de mérito y para la verificación de la sentencia aprobatoria de pacto de cumplimiento.

La función misma del Comité es la de un colaborador en la tarea que tienen los intervinientes de cumplir la sentencia y en la del juez de hacerla ejecutar. Para ello, "comprueba bajo la dirección del juez que los órganos y autoridades o personas obligadas a evitar el daño contingente, a hacer cesar el peligro, la amenaza, la vulneración o agravio sobre los derechos e intereses colectivos o a restituir las cosas al estado anterior, realicen todas las gestiones y acciones derivadas de las órdenes y condenas contenidas en la sentencia" (Consejo de Estado, 2003).

Al respecto, la Corte Constitucional se ha referido al Comité en los siguientes términos: "es una herramienta para la comprobación del cumplimiento de la sentencia, por parte de las autoridades o personas 104 
responsables de poner en peligro o vulnerar los derechos constitucionales colectivos, y permite garantizar el cese de la vulneración o amenaza de los derechos e intereses colectivos dentro del plazo prudencial fijado por el juez" (Corte Constitucional, 2013).

En este orden de ideas, se identifican como características propias del Comité de verificación: 1) Su creación es discrecional del juez, 2) Es de vocación transitoria y su actividad se prolonga hasta la ejecución satisfactoria de la sentencia, 3) No está revestido de autonomía o capacidad decisoria, no es instancia administrativa ni órgano judicial y no comparte las funciones propias del juez, 4) Es un órgano provisional de colaboración para el cumplimiento del fallo, 5) puede asimilarse a un cuerpo auxiliar de la justicia que colabora mediante informes y sirve de apoyo al juez para adoptar las decisiones encaminadas a la ejecución de la sentencia, y 6) Carece del todo de estructura orgánica y por lo mismo su actividad se reduce [...] al análisis de los desarrollos de la decisión judicial y a recomendar determinadas acciones para garantizar su cumplimiento (negrilla fuera del texto original) (Consejo de Estado, 2003).

A pesar de los lineamientos legales y jurisprudenciales, el ejercicio práctico se ha encargado de delinear la metodología, dada la ausencia de regulación clara. En términos generales, el juez en la parte resolutiva de la sentencia ordenará su conformación y señalará quienes lo integrarán. Los interesados podrán solicitar al juez su conformación en la demanda o en el escrito de coadyuvancia con el fin de asegurarse de que haga uso de la figura y podrán solicitar que se les permita ser parte del mismo, así como presentar recomendaciones sobre los temas a tratar y las actividades necesarias para la verificación.

El Comité se reunirá en el tiempo establecido en el fallo o en las actas de las reuniones posteriores y buscará comprobar que se cumplan las órdenes impartidas. En la ejecución de las reuniones se ha encontrado útil que los intervinientes alleguen informes y documentos que den cuenta de las medidas adoptadas para el cumplimiento de lo ordenado. Igualmente, resulta valioso que se aporten las pruebas que, se considera, evidencian la falta de cumplimiento y la suficiencia o efectividad de las medidas que los accionados alegan haber adoptado, así como la propuesta de las medidas que consideren apropiadas para velar por el cumplimiento del fallo.

Como resultado de lo anterior, el Comité podrá elaborar informes o dictámenes que sean puestos a disposición de los intervinientes y del juez para su evaluación, quien a su vez podrá acogerlos para exigir a las 
autoridades correspondientes todas las conductas que resulten necesarias para la protección efectiva de los derechos involucrados (Consejo de Estado, 2003).

En este orden de ideas, deberá entenderse al Comité de Verificación como una herramienta de seguimiento frente a la cual se presentan numerosos cuestionamientos, sin que por ello deje de ser preponderante en la práctica judicial. En términos generales, junto con las demás figuras, materializa el principio de prevalencia del derecho sustancial y el de eficacia, de modo que las garantías constitucionales no resulten vacías ante la ausencia de herramientas que garanticen la efectividad de los derechos colectivos en la práctica.

\subsection{EI Incidente de Desacato como herramienta de coerción para el cumplimiento de la sentencia}

En el marco del Incidente de Desacato, el juez podrá hacer uso de su poder disciplinario para presionar el cumplimiento de sus decisiones. La ley 472 consagró la figura en el artículo 41 como una medida de naturaleza coercitiva en los siguientes términos: "La persona que incumpliere una orden judicial proferida por la autoridad competente en los procesos que se adelanten por acciones populares, incurrirá en multa hasta de cincuenta (50) salarios mínimos mensuales con destino al Fondo para la Defensa de los Derechos e Intereses Colectivos, conmutables en arresto hasta de seis (6) meses, sin perjuicio de las sanciones penales a que hubiere lugar" (Ley 472, 1998).

Adicionalmente, la jurisprudencia ha establecido límites a su ejercicio determinando los presupuestos que el juez debe tener en cuenta para que exista desacato y pueda haber lugar a la imposición de la sanción. En este sentido, "es preciso establecer no solo si materialmente se presenta un incumplimiento de la orden judicial (factor objetivo), sino que además es preciso verificar si está acreditada la negligencia o renuencia de la autoridad (factor subjetivo), por lo que no es posible presumir la responsabilidad por el solo hecho del incumplimiento" (Consejo de Estado, 2011). El juez deberá entonces comprobar que no existe justificación válida para el incumplimiento del funcionario, de tal manera que su proceder se debe a una conducta deliberada y rebelde.

En palabras de la Corte Constitucional (2014): "el incidente es en esencia un procedimiento disciplinario que indaga sobre la responsabilidad subjetiva de la autoridad conminada a materializar el amparo y que, por esa vía, aspira a incidir en el restablecimiento del derecho trasgredido". 106 
En efecto, el juez podrá hacer uso de esta potestad para lograr el cumplimiento de sus órdenes, sin embargo, es claro que la figura busca alcanzar este fin con fundamento en la presión que ejerce sobre la parte condenada, la imposición de una sanción pecuniaria o privativa de la libertad. En últimas, cuando el juez se limita a la imposición de la sanción y no opta por solicitar informes o reclamar la intervención de los mecanismos de control, la figura se torna ineficiente en lograr su fin último: la ejecución oportuna e íntegra de la decisión. La imposición de una sanción de este tipo se limita a ser un mecanismo de presión que en ningún momento garantiza un mejor cumplimiento.

Aunque la finalidad con la que fue concebida la herramienta no fue la imposición de la sanción en sí misma sino la búsqueda de cumplimiento de la sentencia (Consejo de Estado, 2011), esta forma de disuasión se ha tornado ineficiente e inadecuada para asegurar el cumplimiento de la sentencia. La imposición de la sanción no garantiza la protección de los derechos colectivos por el largo tiempo que toma obtener un pronunciamiento definitivo, la dificultad de demostrar el factor subjetivo como requisito esencial para la sanción y por las malas prácticas de las entidades que han encontrado más beneficioso afrontar el costo de la sanción al de cumplir la decisión.

\subsection{Mecanismos de seguimiento a la orden de medidas cautelares}

En lo atinente a la adopción de medidas cautelares dentro del proceso de acción popular, el legislador reguló la materia en los artículos 25 y 26 de la Ley 472 de 1998 con el fin de establecer la especial naturaleza que ostenta la figura cuando se trata de lograr la protección de los intereses colectivos.

A pesar de lo anterior, dicho estatuto no contempla en su literalidad mecanismo o herramienta alguna destinada al seguimiento del cumplimiento de la orden de medida cautelar. Ello se debe a que el modelo adoptado en esta materia, atendiendo al rango supremo de los derechos en cuestión, es de contenido abierto e indefinido, y consagra medidas amplias para prevenir el daño inminente o hacer cesar el que se hubiere causado. Las medidas enunciadas en el artículo 25 dejan, en ese orden de ideas, un amplio margen de aplicación que no encuentra limitación taxativa.

Lo anterior se explica porque, "dada la amplia problemática, los aspectos, matices y situaciones fácticas de la más variada índole que pueden darse en el litigio colectivo, para que las medidas cautelares puedan ser jurídicamente adecuadas y oportunas se requiere 
consolidarlas como esencialmente innominadas, atípicas“ (Bravo, 2013, p. 63), este tipo de protección "reclama ante todo modelos cautelares en blanco sujetos a la iniciativa del juez contencioso para su postulación objetiva, concreción, alcance e imposición en aras de la obtención inmediata del remedio provisional adecuado para hacer prevalecer el interés de la comunidad" (Bravo, 2013, p. 63).

Debe, sin embargo, hacerse alusión a lo dispuesto en el parágrafo 2 del artículo 25 que establece que "Cuando se trate de una amenaza por razón de una omisión atribuida a una autoridad o persona particular, el juez deberá ordenar el cumplimiento inmediato de la acción que fuere necesaria, para lo cual otorgará un término perentorio. Si el peligro es inminente podrá ordenar que el acto, la obra o la acción la ejecute el actor o la comunidad amenazada, a costa del demandado“" (Negrilla fuera del texto original).

El aparte señalado, abre un amplio espectro de posibilidades. En concreto, permitiría que de haberse dictado como medida cautelar una orden de hacer, y frente a su incumplimiento, el juez pueda ordenar la ejecución del acto o la obra por un tercero calificado, con cargo al responsable.

A pesar de lo anterior, no se encuentran casos en los que el juez haya hecho uso de esta potestad y, aunque podría resultar beneficiosa, su rango de aplicación estaría limitado a las órdenes de hacer. Así por ejemplo, no podría utilizarse en el caso en que las órdenes proferidas implican la expedición de actos administrativos o el ejercicio de competencias que solo pueden ser ejecutadas por la autoridad a quien la ley las ha otorgado. Existe entonces una falencia evidente sobre las herramientas con las que el juez cuenta para garantizar el cumplimiento de la orden en estos casos. Por otro lado, resulta importante referirse brevemente a los mecanismos que el Código de Procedimiento Administrativo y de lo Contencioso Administrativo ha dispuesto para el cumplimiento de la orden de medidas cautelares. Ello, por cuanto resulta en cierta medida aplicable a los procesos de acciones populares que son de conocimiento de la jurisdicción contencioso administrativa en virtud del artículo 229 de ese estatuto que dispuso que sería aplicable "en todos los procesos declarativos que se adelanten ante esta jurisdicción" (CPACA, 2011) y dado que el artículo 44 de la Ley 472 permite la aplicación de las disposiciones de la jurisdicción contencioso administrativa en los aspectos allí no regulados, que no se opongan a la naturaleza y finalidad de las acciones populares. 
Una lectura del capítulo XI nos permite identificar ciertas disposiciones que podrían ser útiles a la hora de realizar un seguimiento a la orden de medidas cautelares. Se encuentra pertinente lo señalado en el artículo 235 donde se expresa que la medida "podrá ser modificada o revocada en cualquier estado del proceso, de oficio o a petición de parte, cuando el Juez o Magistrado advierta que no se cumplieron los requisitos para su otorgamiento o que estos ya no se presentan o fueron superados, o que es necesario variarla para que se cumpla, según el caso“"(CPACA, 2011).

Igualmente, el artículo 241 dispone que "el incumplimiento de una medida cautelar dará lugar a la apertura de un incidente de desacato como consecuencia del cual se podrán imponer multas sucesivas por cada día de retardo en el cumplimiento [...] La sanción será impuesta al representante legal de la entidad o director de la entidad pública o al particular responsable del cumplimiento de la medida cautelar por la misma autoridad judicial que profirió la orden, mediante trámite incidental y será susceptible de los recursos de apelación en los procesos de doble instancia y de súplica en los de única instancia [...] El incumplimiento de los términos para decidir sobre una medida cautelar constituye falta grave" (CPACA, 2011).

Dichos mecanismos podrían llenar el vacío de la ley 472 frente al cumplimiento de la orden de medida cautelar. Sin embargo, no resultan novedosos en su consagración y presentan como punto más fuerte la figura del desacato que, como ya se ha explicado, suscita serios cuestionamientos frente a su efectividad.

Aclarado lo anterior, se considera que una forma de contrarrestar el efecto negativo que tiene para la eficacia del proceso el incumplimiento generalizado de las órdenes de medidas cautelares, es otorgar una consecuencia adversa en el fallo condenatorio a la omisión de la entidad demandada. Creemos que cuando opta por desconocer el mandato de medidas cautelares pone deliberadamente en riesgo la protección de los derechos colectivos. Más si se tienen en cuenta los numerosos casos en que su renuencia o tardanza ha resultado en la concreción del daño en acciones de carácter preventivo o ha tornado consecuencias adversas en daños irremediables.

A pesar del vacío normativo, creemos que no existe ningún impedimento para que el juez haga uso de las figuras consagradas para el seguimiento de la sentencia con el fin de lograr el cumplimiento de las órdenes de medidas cautelares o que, incluso, pueda llegar a idear mecanismos nuevos de verificación. Ello se debe a que el espectro de las acciones 
populares se encuentra en su totalidad cobijado por la prevalencia del derecho sustancial, la importancia de los intereses involucrados y por el principio de eficacia, que fundamentan los amplios poderes que han sido otorgados al juez con el fin de asegurar la efectividad de la protección de los derechos colectivos.

\section{HALLAZGOS, FORTALEZAS Y RETOS FRENTE A LOS MECANISMOS DE SEGUIMIENTO ESTABLECIDOS POR LA LEY 472 DE 1998}

En primer lugar, debe alabarse que el legislador haya optado por la introducción de figuras innovadoras concebidas específicamente para el proceso de acciones populares. La novedad se revela, principalmente, en el otorgamiento de facultades al juez que se extienden en el tiempo más allá de la ejecutoria del fallo de mérito y que le permiten conservar potestad una vez terminado el proceso con el único fin de lograr el cumplimiento de las órdenes proferidas. Esto facilita el proceso de verificación puesto que el cumplimiento de la sentencia no se deja únicamente a voluntad de la parte condenada sino que se garantiza que exista un papel activo del juez en la verificación.

En particular, la figura del Comité de Verificación genera un escenario novedoso que incrementa la eficacia y disminuye los términos para lograr el cumplimiento. Ello se debe a que se trata de un espacio al que concurren todos los interesados de forma personal y directa, propiciando una interacción cara a cara entre la parte actora, los demandados, la sociedad civil y demás intervinientes. Ello permite la construcción de fórmulas de arreglo conjuntas, que de ser logradas, cuentan por ello con un alto grado de aprobación entre los intervinientes, que asumen los compromisos

Las reuniones posteriores al fallo que realiza el Comité, permiten además que el fallo pueda continuar construyéndose y adaptándose a los distintos escenarios que se presentan en la etapa de ejecución, con el fin último de lograr la protección efectiva de los derechos involucrados. Así, aunada a la potestad que el juez conserva para esta etapa, su labor abre paso a un fallo viviente, que permite que en la ejecución pueda hacerse frente a los cambios y formular propuestas para lograr el cumplimiento.

\subsection{La necesidad de establecer parámetros metodológicos en la conformación y ejecución del Comité de Verificación}

A pesar de las bondades y de la novedad de esta institución, la práctica ha develado retos y debilidades en su ejecución. En primera medida, se 110 
encuentra que la amplitud de los términos empleados en la regulación del Comité de Verificación ha suscitado serias dudas sobre la metodología que debe seguirse una vez ha sido conformado.

Se identifica en la práctica un vacío normativo importante. La ley no se encargó de definir cómo debe actuar el Comité sino que se limitó a otorgar potestad al juez para su conformación, por lo que la implementación de la figura varía de caso a caso. Así por ejemplo, el juez podrá limitarse a ordenar la conformación del Comité de Verificación sin que se defina quién deberá dirigir sus reuniones y en qué lugar o cuándo habrán de realizarse, quedando a facultad de quienes lo integren determinar los pormenores de su operatividad.

Se generan entonces cuestionamientos sobre quién deberá coordinar o presidir el Comité. Es claro que quien dirija las reuniones tendrá un papel relevante a la hora de realizar el seguimiento, puesto que bajo su dirección se definirán las tareas a asignar, los plazos y los responsables. En consecuencia, el coordinador cumple una tarea que reclama responsabilidad e imparcialidad. En algunos casos, los conflictos que genera la tarea de su designación, han llevado al escenario absurdo en el que la parte demandada se arroga la facultad de dirección, lo que termina poniendo en riesgo el cumplimiento de las órdenes y lleva que actúe como vigilante de su propio cumplimiento.

Al respecto, el Ministerio Público, como garante de la protección de los derechos, debería asumir un papel activo en la implementación de la figura y podría ser fundamental en la resolución de las vicisitudes. Desde el punto de vista metodológico, podría contribuir fungiendo como coordinador imparcial de las reuniones, participando activamente en su desarrollo e incluso proporcionando las instalaciones para su realización a modo de territorio neutral. Su participación pasiva deja un vacío significativo en el desarrollo de las actividades del Comité y propicia confrontaciones entre los involucrados que debilitan el proceso de ejecución del fallo.

Por otro lado, se presentan inconvenientes frente a la determinación de quiénes deberán integrar el Comité, sus funciones y las consecuencias que debe acarrear la inasistencia de las partes involucradas. Ello, dado que no existe ninguna disposición que constriña a una actividad diligente por parte de quien coordina o interviene, ni mucho menos que establezca una consecuencia jurídica adversa frente a la inasistencia, lo que propicia un alto índice de inasistencia y de audiencias de bajo rendimiento. 
Tampoco se encuentra regulación alguna frente a cómo deberá surtirse el diálogo entre el juez y el Comité. Esto repercute directamente sobre el peso que el primero deberá o no otorgar a los informes, actas y demás documentos que sean aportados en el marco de las reuniones de este último. De este modo, puede que la información evidencie un comportamiento renuente por parte de la parte condenada sin que esto determine la imposición de consecuencia adversa alguna por parte del juez.

Visto lo anterior, "no basta con que el juez ordene la creación del Comité, es pertinente que cumpla el rol de coordinador, orientador y líder de su trabajo. Es útil que los jueces y magistrados entiendan la importancia de esta figura y propongan, junto con el Ministerio Público, lineamientos y directrices que permitan determinar las obligaciones de sus integrantes, las fechas de sus reuniones y las consecuencias del incumplimiento de los acuerdos“" (Benavides, et al., 2006, p. 39).

En todo caso, resulta esencial que en las reuniones se determinen como mínimo tareas claras, tiempos específicos y responsables. La tarea del Comité consiste en ordenar la parte resolutiva de la sentencia, esto permite que se distribuya en el tiempo la ejecución de lo ordenado, facilita la tarea de determinar con claridad los responsables y proporciona información que permite identificar cuándo se está incumpliendo el fallo. En consecuencia, el cumplimiento podrá evaluarse en periodos específicos de tiempo y frente a tareas definidas que permitan determinar el grado de ejecución de la decisión.

Así mismo, es urgente que se implemente una metodología que considere los distintos factores que pueden influenciar la evaluación del grado de cumplimiento del fallo. Ello, porque las soluciones metodológicas adoptadas como producto de la praxis se tornan insuficientes en ciertos escenarios que requieren de metodologías detalladas a la hora de evaluar en qué medida existe un cumplimiento y una protección real de los derechos involucrados.

Así por ejemplo, ciudadanos del barrio Restrepo de la ciudad de Bogotá instauraron acción popular contra la Alcaldía Mayor de Bogotá, Alcaldía Local Zona 15 Antonio Nariño y la Secretaría Distrital de Ambiente con ocasión a los altos grados de contaminación auditiva que los establecimientos de comercio generan en el sector y que han afectado la salud de una comunidad integrada por niños y adultos mayores. Se pretendía que las autoridades demandadas ejercieran las acciones necesarias con el fin de que los negocios que producían ruido cumplieran con la normatividad ambiental sobre contaminación auditiva y 112 
dispusieran de inmediato las medidas para las obras de control de ruido e insonorización (Acción Popular, 2007).

Dentro del proceso, las entidades demandadas se opusieron a las pretensiones alegando el cumplimiento de sus deberes legales al ejercer vigilancia sobre el sector y realizar operativos de medición de ruido. A pesar de ello, el fallo de primera instancia (Acción Popular, 2007) concedió la protección de los derechos colectivos invocados. Para ello, dio órdenes que incluyen actuaciones complejas como la conformación de mesas de concertación, la implementación de medidas administrativas para la insonorización, la presentación de informes de medición y la conformación del Comité de verificación, algunas de ellas extendidas hasta 12 meses en el tiempo.

En casos como el expuesto, se presentan numerosos inconvenientes a la hora de establecer cuándo se entiende un cumplimiento total y real de las órdenes proferidas. Situaciones similares posibilitan que los demandados, y en ocasiones los jueces, entiendan ejecutado el fallo por el cumplimiento formal de las obligaciones legales y constitucionales correspondientes, por ejemplo, si se han efectuado periódicamente visitas y mediciones de ruido o se han iniciado procesos sancionatorios ambientales contra los establecimientos. Sin embargo, estas medidas no aseguran que disminuyan los niveles de ruido o la afectación de los derechos colectivos de los afectados, puede entonces existir un cumplimiento de las obligaciones legales sin que la comunidad vea aminorada su situación. Lo anterior es posible porque los procesos sancionatorios ambientales y las problemáticas de ruido incluyen variantes y complicaciones sociales adicionales frente a las que un cumplimiento formal puede no garantizar el alivio de los perjudicados.

La verificación requerirá medidas metodológicas especializadas que permitan evaluar la ejecución de las órdenes según la disminución efectiva de la vulneración y el real alivio de los afectados, y no frente a la mera satisfacción de las obligaciones legales por parte de las entidades. Esto resulta fundamental para fortalecer la labor del Comité de Verificación y para asegurar la resolución adecuada y efectiva de los conflictos, previniendo que se perpetúe indefinidamente en el tiempo la intervención de la rama judicial en los mismos asuntos jurídicos.

\subsection{El Comité de Verificación como mecanismo de seguimiento preponderante}

A partir de un examen de casos se han identificado ciertos patrones en el ejercicio ciudadano de las acciones populares con respecto a la ejecución 
de las órdenes proferidas por el juez. En primer lugar, se observa que de los mecanismos dispuestos por la ley 472, el Comité de Verificación se ha convertido en la figura preponderante a la hora de garantizar el cumplimiento de las órdenes proferidas.

En términos generales, se encuentra que es poco común que el juez sea creativo empleando sus amplias potestades y que la figura del auditor cuenta únicamente con una reflexión teórica, de forma que no se ha encontrado ningún caso que demuestre su utilización práctica. Las distintas figuras legislativas han sido de esta forma relegadas para dar paso a una aplicación predominante del Comité de Verificación.

El Consejo de Estado (2003) ha sostenido que la figura del auditor fue designada específicamente para el caso de la sentencia aprobatoria de pacto y que el Comité pertenece al escenario de la sentencia de mérito, con base en una lectura separada de los artículos 27 y 34 de la Ley 472 de 1998. Sin embargo, la práctica de los jueces ha evidenciado la posibilidad de extender la figura del Comité al escenario del pacto del cumplimiento.

Lo anterior, encuentra asidero en que es facultativo del juez determinar la utilización de cualquiera de ambas figuras y en que nada en la ley lo prohíbe. Tanto el artículo 27 como el 34 enfatizan que el juez "podrá" optar o no por el uso de las figuras señaladas y se fundamentan en la competencia que conserva el juez para lograr el cumplimiento una vez en firme la decisión. Se reitera que la amplia facultad otorgada al juez para la etapa de ejecución, puede dar lugar no solo a la extensión de la figura a un escenario no regulado sino incluso a la creación o adopción de nuevos mecanismos que le permitan asegurar la efectividad de lo ordenado. No existe ningún impedimento de índole legal o práctico para que la figura del artículo 34 (el Comité) pueda entonces extenderse al escenario de la sentencia aprobatoria de Pacto de Cumplimiento.

Ello se evidencia en que los jueces han optado en la práctica por nombrar un Comité de Verificación para la vigilancia de la sentencia aprobatoria de pacto de cumplimiento, figura que ha sido denominada como el Comité de seguimiento del pacto, aunque no hubiese sido concebida legalmente para este escenario.

A modo de ejemplo, en el 2004 se presentó acción popular por un grupo de ciudadanos contra la Corporación Autónoma Regional del Centro de Antioquia (Corantioquia) y una persona particular con el fin de obtener la protección del derecho colectivo al goce de un ambiente sano, debido 114 
a la desviación del cauce y canalización de las aguas de la quebrada "Los Barrera" sin la autorización de Corantioquia, quien omitió tomar medidas una vez enterada de la situación. Dentro del proceso el Tribunal Administrativo de Antioquia convocó a audiencia de pacto de cumplimiento en el marco de la cual los intervinientes llegaron a pacto para la protección de los derechos invocados. El proceso finalizó con la sentencia de 11 de mayo de 2005 que aprobó el acuerdo logrado y que creó un Comité de Verificación en su parte resolutiva "Para dar cumplimiento al inciso final del artículo 27 de la Ley 472 de 1998 * (Tribunal Administrativo de Cundinamarca, 2005).

Igual proceder puede encontrarse en el caso del botadero de basura Magic Garden en el que se interpuso una acción popular de carácter preventivo orientada a proteger los derechos colectivos al medio ambiente sano, al equilibrio ecológico, al aprovechamiento adecuado de los recursos naturales, a una apropiada infraestructura de servicios públicos y a la prevención de desastres técnicamente previsibles, entre otros (Benavides, et al., 2006, p. 42). Allí, luego de llegar a un pacto que beneficiara al medio ambiente, a los recursos naturales y a la comunidad residente del Archipiélago de San Andrés, Providencia y Santa Catalina, el Tribunal Administrativo profirió sentencia consignando los compromisos y ordenó se constituyera un Comité de Verificación y Seguimiento, con el fin de realizar una labor de veeduría respecto de lo acordado en el pacto (Benavides Burbano, et al., 2006, p. 42).

Los casos expuestos muestran que, ante la terminación del proceso de acción popular por haberse alcanzado un pacto, los jueces pueden optar por conformar el Comité de Verificación, lo que permite concluir que la figura ha sido efectivamente implementada como herramienta de seguimiento de la sentencia aprobatoria del pacto de cumplimiento y que "en cuanto a la diferencia entre Auditoría o Comité de Verificación, y la procedencia exclusiva de la última figura solo en caso de terminar el proceso con sentencia de mérito, la práctica demuestra una vez más que la distinción carece de efectos de fondo, y que el juez podrá, a discreción, escoger aquella que resulte a su juicio más oportuna, pertinente y productiva en términos de resultados" (Benavides Burbano, et al., 2006, p. 43).

La figura del Comité resultará en la mayoría de los casos la herramienta predilecta del juez en la etapa de ejecución, aún por encima de las facultades amplias y suficientes que le permiten un espacio de creatividad en la implementación de su decisión. En la práctica, encontramos que ello se debe a la dificultad de realizar una verificación 
personalizada por factores de tiempo y espacio: es bien sabido que los jueces atienden gran cantidad de expedientes por despacho y que la celeridad y correcta administración de justicia les impide centrarse de forma detallada en la ejecución de cada uno. En igual sentido, una buena cantidad de los casos de acciones populares son de impacto nacional de modo que el juez de conocimiento puede no encontrarse territorialmente en el lugar de los hechos, lo que hace aún más difícil que realice por sí mismo la verificación y tome medidas que resulten efectivas en el lugar de los hechos.

Por las razones expuestas, la figura del Comité resultará más expedita y eficiente en el ejercicio de las labores de verificación, puesto que se conformará con el único fin de fungir de veedor del cumplimiento de las órdenes y porque permite que el proceso de ejecución sea evaluado en concreto e incluso en el lugar en que se da la afectación de los derechos colectivos con la participación de todos los involucrados.

\subsection{La indebida conformación del Comité de Verificación}

Adicionalmente, se encuentra que en la práctica los vacíos normativos en materia de las reglas que deben regir el trabajo del Comité y su conformación han propiciado problemas en su correcta conformación. En gran parte de los casos, el juez olvida incluir a todas las partes interesadas en su actividad.

En concreto, se encuentran casos en los que el juez olvida convocar al coadyuvante y este se ve obligado a solicitar luego que se le permita participar. A modo de ejemplo, en el caso de la acción popular interpuesta ante la problemática de los pick ups en el Archipiélago de San Andrés, Providencia y Santa Catalina, no solo se omitió incluir a la parte coadyuvante sino que se tuvo que solicitar que se permitiera al apoderado de la parte actora actuar dentro de las reuniones. En este caso específico, ello resultaba fundamental puesto que el aludido era también el principal contacto que tenía el Grupo de Acciones Públicas con el caso y quien había participado directamente en la elaboración de la acción y en las actuaciones que tuvieron lugar durante el proceso.

El caso es solo una muestra de una tendencia generalizada en el actuar de los jueces a la hora de determinar la composición del Comité. Se hace entonces imperativo que se corrija esta práctica puesto que la parte coadyuvante presenta un interés directo en la protección de los derechos colectivos a favor de los cuales interviene y se trata, en últimas, de la protección de sus propios derechos. 


\subsection{La necesidad de reforzar el papel del Ministerio Público en la búsqueda de eficacia de las decisiones}

Ahora bien, un estudio sobre el ejercicio del Comité de Verificación permite sustraer algunas conclusiones frente al rol que ha sido asignado al Ministerio Público. Se encuentra de una revisión de las actas de reuniones del Comité de Verificación, que su intervención está lejos de ser la exigida para la garantía de los derechos colectivos.

La función otorgada al Ministerio Público por el constituyente es clara frente a la labor que le corresponde en la protección de los derechos humanos. Así, el artículo 277 de la Constitución señala que el Procurador General de la Nación, como supremo director del Ministerio tendrá como función “ 2. Proteger los derechos humanos y asegurar su efectividad, con el auxilio del Defensor del Pueblo, 3. Defender los intereses de la sociedad, 4. Defender los intereses colectivos, en especial el ambiente, 5. Velar por el ejercicio diligente y eficiente de las funciones administrativas [...] 7. Intervenir en los procesos y ante las autoridades judiciales o administrativas, cuando sea necesario en defensa del orden jurídico, del patrimonio público, o de los derechos y garantías fundamentales" (Constitución Política de Colombia, 1991). En similar sentido, el artículo 282 constitucional señala que corresponde al Defensor del Pueblo velar por la promoción, el ejercicio y la divulgación de los derechos humanos, para lo cual ejercerá como funciones: "1. Orientar e instruir [...] en el ejercicio y defensa de sus derechos ante las autoridades competentes o entidades de carácter privado [...] 5. Interponer acciones populares en asuntos relacionados con su competencia" (Constitución Política de Colombia, 1991). En términos generales, es la institución del Estado responsable de impulsar la efectividad, de proteger y defender los derechos humanos y prevenir sus violaciones (Defensoría del Pueblo, 2003-2016).

En virtud de lo anterior, la Ley 472 decidió otorgar un papel preponderante al Ministerio Público dentro del proceso de las Acciones Populares. Por ejemplo, cuando expresamente se nombra como uno de los facultados para ejercer la acción, se contempla que el juez de conocimiento deba notificarlo del auto admisorio con el fin de ponerlo al tanto de la vulneración y para que ejerza su función de garante de los derechos involucrados, cuando demandó que su asistencia a la Audiencia Especial de Pacto de Cumplimiento fuese obligatoria so pena de sanción y, en la etapa de ejecución, cuando dispuso su integración como parte del Comité de Verificación. 
A la luz de lo expuesto, la Procuraduría, sus agentes o delegados y el Defensor del Pueblo están llamados a ejercer un rol preponderante durante el proceso judicial y en la etapa de verificación. En este sentido, si estas entidades han sido creadas con el fin de defender, proteger y difundir los derechos colectivos, este es un espacio fundamental en el que deberán actuar para cumplir con ese propósito. El Ministerio Público es "un organismo al cual se le confía la función de control sobre el correcto cumplimiento del orden jurídico, la acción popular [es] un excelente aliado en tal función, por cuanto atiende la problemática de la comunidad de manera directa, evitándole trámites administrativos que no conducen a la solución del problema“" (Salazar, 2010, p. 75).

A pesar de lo anterior, la actuación del Ministerio en la Audiencia Especial de Pacto de Cumplimiento suele ser insustancial y escasa. Así mismo, son pocas las ocasiones en que el Ministerio opta por hacer uso de su facultad de presentar oficiosamente acciones populares en defensa de los derechos colectivos, como también ha resultado insuficiente su colaboración y apoyo a las comunidades que actúan en defensa de sus derechos.

En lo atinente a la etapa de ejecución, la actuación del delegado del Ministerio Público también ha presentado dificultades. Así por ejemplo, de una revisión de las actas de las reuniones del Comité de Verificación que se han dado en casos en los que ha participado el Grupo de Acciones Públicas de la Universidad del Rosario, se encuentra que la participación del representante se limita, en muchos casos, a la reiteración de lo dicho por otros intervinientes, que participa en pocas ocasiones o incluso no asiste a las audiencias a las que es convocado.

En el caso denominado por la clínica jurídica como "Pick ups" se interpuso una acción popular para lograr la protección de los derechos al goce de un ambiente sano, a la existencia de un equilibrio ecológico, al manejo y aprovechamiento racional de los recursos naturales, a la protección de áreas de especial importancia ecológica y a la seguridad y salubridad públicas, con ocasión a los altos niveles de ruido que genera en el Archipiélago de San Andrés, Providencia y Santa Catalina el uso indiscriminado de los altoparlantes. Dentro del proceso judicial se han realizado dos reuniones del Comité de Verificación cuyas actas (Acta, 2016) dejan constancia de lo cortas y poco propositivas intervenciones del Ministerio, que se limita a señalar aspectos frente a la intervención de los otros participantes y a asegurar que garantizará que en los operativos de la policía no se lesione los derechos de las personas, sin que se aporte significativamente a la construcción del plan de acción o se refiera al incumplimiento de las entidades accionadas (Acta, 2016). 
La pobre intervención del Ministerio se hace aún más evidente en el caso denominado Quinta de Mutis (Acción Popular, 2008), acción popular interpuesta para obtener el amparo de los derechos colectivos al goce del espacio público, la utilización y defensa de los bienes de uso público y la seguridad pública, vulnerados por la Alcaldía Local de Barrios Unidos en Bogotá. En el seguimiento al fallo proferido el 10 diciembre de 2008 por la Sección Primera de la Sala de lo Contencioso Administrativo del Consejo de Estado, se realizaron cinco audiencias para la verificación del cumplimiento de la sentencia durante los años 2012 a 2014. De un estudio de los autos y actas que dan constancia de las diligencias para verificación, se encuentra que de las cinco audiencias celebradas (Acta, 2012) (Acta II, 2012) (Acta III, 2012) (Acta, 2013) (Acta, 2014), el Ministerio Público no acudió a dos y en las restantes sus intervenciones fueron vacías de todo contenido (en un caso reitera lo dicho por el juez sobre la importancia del Comité y en otro se limita a hacer una pregunta en toda la audiencia), sin aludir en ningún caso al cumplimiento del fallo, ser propositivo o referirse siquiera al estado de vulneración de los derechos colectivos.

Lo expuesto, muestra que su intervención podría mejorarse utilizando las herramientas diversas con que cuenta en materia de acciones populares. En efecto, el Defensor del Pueblo podrá, entre otros: "Colaborar en la elaboración de la demanda en las acciones populares [...] así como brindar el apoyo y la asesoría necesarios para su interposición, interponer acciones populares, coadyuvar, intervenir en las acciones populares que se interpongan sin la intermediación de un apoderado judicial, intervenir en los Pactos de Cumplimiento en las acciones populares, promover y divulgar los derechos e intereses colectivos y la forma de protegerlos, organizar el Registro Público centralizado de las Acciones Populares y manejar y administrar el Fondo para la Defensa de los Derechos e Intereses Colectivos" (Defensoría del Pueblo, 2007).

Aunque la Defensoría ha hecho uso de sus facultades, interponiendo acciones populares y participado en los procedimientos, el ejercicio de las herramientas puede ser mejorado. Así por ejemplo, la Defensoría en uso de sus facultades constitucionales (Defensoría del Pueblo, 20032016) de mediador ${ }^{2}$ podría intervenir cuando tenga conocimiento de una problemática de vulneración de derechos colectivos acercando a las partes involucradas con el fin de evitar la concreción de un daño o lograr la protección del derecho; también podría incluso denunciar

2 Según el portal web de la Defensoría, es función del Defensor del Pueblo: "12. Ser mediador entre los usuarios y las empresas públicas o privadas que presten servicios públicos, cuando aquellas lo demanden, en defensa de los derechos que se presuman violados. 
públicamente el desconocimiento de los derechos colectivos ${ }^{3}$. En materia de difusión ${ }^{4}$, se hace necesaria la actualización de la cartilla expedida por la Defensoría sobre el funcionamiento de la acción (Defensoría del Pueblo, 2007) dado que la información actual excluye modificaciones legislativas y jurisprudenciales importantes que se han convertido en verdaderos obstáculos para el ciudadano.

En igual sentido, podría darse mayor y mejor utilización a la coadyuvancia, que es un mecanismo poderoso dentro de los procesos de acción popular y una herramienta directa para defender los intereses colectivos dentro del proceso judicial. Así mismo, su participación en la Audiencia Especial de Pacto de cumplimiento podría ir más allá del cumplimiento del requisito de asistencia obligatoria para centrarse en intervenciones propositivas que ayuden al juez y a los intervinientes en la tarea de llegar a un acuerdo y lograr lo antes posible la protección de los derechos colectivos.

Frente a la etapa de ejecución y verificación del fallo, debe establecerse como mínimo la asistencia obligatoria del Ministerio a las reuniones del Comité de verificación y un mejoramiento en el contenido de sus intervenciones, de manera que sea propositivo y asuma su papel como defensor de los intereses colectivos. Además, podría ser un actor fundamental en la elaboración e implementación de directrices metodológicas para la conformación y ejecución de las reuniones del Comité de verificación. Ello, debido a que es la entidad constitucionalmente encargada de impartir lineamientos en materia de protección de los derechos humanos(Defensoría del Pueblo, 2003-2016).

\section{Los amplios poderes del juez como fundamento de la adopción y creación de nuevos mecanismos de seguimiento dentro del proceso de Acción Popular}

En ejercicio de las amplísimas facultades que le han sido otorgadas al juez dentro de los procesos de acción popular, se encuentran casos en que la complejidad del asunto ha ameritado la creación de figuras distintas a

\footnotetext{
3 Según el portal web de la Defensoría, es función del Defensor del Pueblo: "19. Rendir informes periódicos a la opinión' pública sobre el resultado de las investigaciones adelantadas por la Defensoría del Pueblo y denunciar públicamente el desconocimiento de los derechos humanos y el derecho internacional humanitario. 4 Según el portal web de la Defensoría, es función del Defensor del Pueblo: "21. Celebrar convenios con establecimientos educativos y de investigaciones nacionales e internacionales, para la divulgación y promoción de los derechos humanos."

5 Según el portal web de la Defensoría, es función del Defensor del Pueblo: "5. Impartir las directrices para instar a las organizaciones privadas para que se abstengan de desconocer un derecho [...] 8. Impartir los lineamientos para adelantar las estrategias y acciones que se requieran para garantizar los derechos de los sujetos de especial protección constitucional".
} 
las consagradas en la Ley 472 de 1998 y que abren la puerta para que en el futuro puedan adoptarse figuras implementadas por otras jurisdicciones en la búsqueda de efectividad de las decisiones judiciales.

En primer lugar, debe resaltarse que los jueces de la jurisdicción constitucional cuentan con herramientas propias para la verificación del cumplimiento de las órdenes proferidas en el marco del proceso de acción de tutela. Al respecto, se encuentra, en primera medida, la figura de la Sala Especial de Seguimiento de la sentencia.

Esta herramienta es el resultado de la aplicación de los poderes que ha conferido el decreto 2591 de 1991 al juez de tutela ${ }^{6}$, de conformidad con el cual "el juez [...] mantendrá la competencia hasta que esté completamente restablecido el derecho o eliminadas las causas de la amenaza“"(Decreto 2591, 1991).

Es en desarrollo de esta disposición que la Corte Constitucional puede conformar una Sala que garantice el cumplimiento de las órdenes proferidas en el marco de la acción, por ejemplo, con el fin de sobrepasar un estado de cosas inconstitucional. La sala profiere, para ello, autos que dan cuenta del avance en el cumplimiento y que emiten órdenes sobre la materia. Adicionalmente, se crea una página web que condensa todos los autos y los pone en conocimiento de la ciudadanía. Su labor podrá tener tal envergadura que implique la presentación de informes por parte del Gobierno Nacional que den cuenta de las fallas y ajustes que deban implementarse. Por último, el escenario de la Sala permite la realización de Audiencias Especiales de Seguimiento que permiten una participación de las autoridades supervisadas, los órganos de control, la sociedad civil y entes de control, propiciando un espacio abierto de intervención.

Como ejemplo de ello, se destaca la sentencia T-025 de 2004, frente a la cual se estableció una Sala Especial de Seguimiento a la Sentencia y sus autos de cumplimiento, conformada por magistrados de la alta corporación con el fin de hacer frente al estado de cosas inconstitucional

6 De conformidad con el Auto 045 de 2004 proferido por la Corte constitucional (M.P. Rodrigo Escobar Gil): "Conforme con las directrices trazadas en el Decreto 2591 de 1991, la garantía y efectividad del cumplimiento de las sentencias de amparo exigen del juez constitucional una actuación de doble vía: (i) la primera, de naturaleza objetiva y consustancial a la vigencia del mecanismo de amparo, la cual se concreta en la adopción de todas las medidas que sean necesarias para lograr la protección real y efectiva de los derechos fundamentales protegidos [..](arts. 23 y 27); y (ii) la segunda, esencialmente subjetiva, materializada en la imposición de sanciones a las autoridades o particulares que se hayan resistido a su cumplimiento, lo que incluye tramitar el respectivo incidente de desacato (arts. 37 y 52) [...] sin perjuicio de que se sancione o no al funcionario obligado a obedecer el fallo, el juez constitucional tiene el deber de asegurar su total cumplimiento si ello no ha ocurrido por vía del desacato." 
que se presenta como consecuencia de la vulneración masiva, generalizada y reiterada de los derechos de la población desplazada, por causas asociadas al conflicto armado interno y debido a problemas de tipo estructural y sistémico relacionados con la ausencia de políticas públicas idóneas y eficaces para su prevención y atención(Auto, 2013).

A pesar de los beneficios, la institución tiene un campo de aplicación limitado dado que resulta procedente únicamente en casos que son de conocimiento de una alta corte y cuando se trata de temáticas de alta complejidad y trascendencia ${ }^{7}$. De igual forma, existen diversos factores que pueden afectar su utilización y que han contribuido a la formación de una percepción de decaimiento y desuso. Puede resultar poco funcional que el mecanismo dependa casi exclusivamente del empeño y trabajo del magistrado encargado dado que la verificación puede verse seriamente afectada cuando exista una rotación de los magistrados o como resultado de la congestión de sus despachos.

Con todo, consideramos que la figura ha surtido efectos positivos en los casos en los que ha sido implementada y es un avance importante en la búsqueda de mecanismos que aseguren la efectividad de los derechos una vez finalizado el proceso judicial. Por ello, y dadas las similitudes que existen entre la potestad otorgada al juez de tutela mediante el Decreto 2591 y la otorgada al juez de acción popular en la Ley 472, no existe impedimento para que esta figura sea acogida y adaptada en el marco de la Jurisdicción Contencioso Administrativa. En otras palabras, el Consejo de Estado podría conformar una Sala de Seguimiento y realizar audiencias públicas con el fin de verificar el cumplimiento de órdenes proferidas en los procesos de acción popular, en particular, en los que observe la existencia de varias decisiones relacionadas con una temática de alto impacto social y en los que exista una vulneración de considerable envergadura de los derechos colectivos que afecte una o varias comunidades.

Por otra parte, consideramos que en el actuar de la Jurisdicción Contencioso Administrativa pueden encontrarse ejemplos de casos en los que el juez ha innovado en la adopción de figuras de seguimiento y que podrían extenderse a otras jurisdicciones. El caso del Fallo de acción popular proferido por el Consejo de Estado el 28 de marzo de 2014 sobre

7 Muestra de ello es que se haya implementado en pocas ocasiones. Actualmente se encuentran: La Sala Especial de Seguimiento a la Sentencia T-760 de 2008, proferida como respuesta a la violación generalizada del derecho fundamental a la salud que tiene como principal causa las fallas de regulación del Sistema General de Seguridad Social en Salud y la Sala Especial de Seguimiento de la T025 de 2004, en materia de derechos de la población desplazada. 
la protección del Río Bogotá resulta particularmente ilustrativo en la materia.

Ante la longitud y complejidad de las problemáticas involucradas, la alta corporación creó instituciones originales e innovadoras dirigidas a realizar un seguimiento juicioso del fallo. Dentro de los mecanismos se resalta la creación del Observatorio Regional Ambiental y de Desarrollo Sostenible del Río Bogotá como “instrumento de dirección y gestión integral de cuenca hidrográfica que incluye la gestión ambiental, el fortalecimiento institucional y la cohesión social" (ORARBO, s.f). Se trata de una herramienta virtual que "propicia una interacción entre los diferentes actores [...] donde pueden dar a conocer sus experiencias, obtener información y [...] fortalecer sus procesos de toma de decisiones, investigación y articulación con los demás actores de orden institucional, empresarial, no gubernamental o comunitario" (ORARBO, s.f).

En el fondo, se trata de un portal web establecido como mecanismo de seguimiento a una sentencia de acción popular que resulta poderoso para el cumplimiento de las órdenes impartidas. Su valor reside en que permite evaluar la ejecución del fallo a partir de un elemento novedoso: los indicadores de cumplimiento. Cada indicador es generado por componente, por seguimiento a la sentencia, por municipio, región y por entidad. Sus componentes exponen con claridad la información, los avances, la conformación y las órdenes, lo que permite que la sociedad civil y los demás actores involucrados pueda entender qué se ha cumplido, en qué grado y en cuáles aspectos hace falta avanzar, facilitando la tarea del juez de verificación.

Esta figura de creación jurisprudencial es evidencia de la gran cantidad de medidas que pueden ser instituidas por el juez con el fin de lograr la ejecución de sus órdenes y la protección de los derechos vulnerados o amenazados. La construcción de indicadores de cumplimiento es un ejemplo a seguir en materia del ejercicio de los amplios poderes del juez y un modelo que puede ser adaptado en casos futuros de acción popular y otras acciones populares.

Lo expuesto es una muestra de la versatilidad de los mecanismos que pueden ser implementados para el seguimiento de las sentencias dentro de los procesos de acción popular. Las figuras de consagración legal, como el caso del auditor y el Comité de Verificación, son en últimas una muestra del espectro frente al cual puede actuar el juez. Su potestad permite, tanto el intercambio de las herramientas ya consagradas para su 
uso y aprendizaje en jurisdicciones distintas, como la creación de modelos novedosos que buscan una protección de derechos más allá del fallo favorable.

\section{CONCLUSIONES}

De lo expuesto, se pueden resaltar como grandes aspectos: i) Existen diversas herramientas vigentes que permiten lograr un seguimiento a las órdenes proferidas en el marco del proceso de acción popular, ii) existe, por regla general, una actitud poco propositiva de los jueces y del Ministerio Público que debe ser reforzada y transformada a la hora de realizar un seguimiento efectivo en la protección de los derechos colectivos y iii) la ampliación y fortalecimiento de los mecanismos existentes será posible con base en los amplios poderes que son conferidos al juez de acción popular.

En relación con el primer aspecto, se encuentra que la ley ha dispuesto como fundamento de toda herramienta de verificación la posibilidad del juez de conservar poder una vez el proceso judicial ha concluido, con el fin último de lograr la ejecución de lo ordenado. A partir de ello se consagran como mecanismos de seguimiento: el Comité de verificación, el Auditor y los propios poderes del juez que le permiten tomar las medidas que sean necesarias para lograr el cumplimiento de sus órdenes.

Con respecto a lo segundo, se ha comprobado que en la verificación se ha optado preeminentemente por conformar el Comité de Verificación para el seguimiento de la sentencia. Lo anterior muestra el desuso práctico de la figura del Auditor y una actitud, en general, pasiva de los jueces que son poco creativos a la hora de utilizar los poderes que les ha otorgado la ley para garantizar la ejecución de sus órdenes.

A pesar de que el Comité es el pilar de las herramientas disponibles, se evidencian fuertes vacíos en materia de su reglamentación e implementación. La práctica devela retos en lograr un marco regulatorio por el que deba regirse su conformación y el desarrollo de sus reuniones. El establecimiento de parámetros metodológicos resultará de suma importancia a la hora de reforzar el papel de esta herramienta y alcanzar la efectividad de las reivindicaciones logradas durante la etapa procesal.

Por otro lado, el panorama expuesto hace vital que se fortalezca el rol del Ministerio Público como garante y promotor de los derechos humanos en los procesos de acción popular. Se encuentra que en la mayoría de los casos evaluados, sus representantes han faltado al mandato 124 
constitucional que les ha sido otorgado, bien porque no intervienen propositivamente durante el proceso o porque durante la etapa de ejecución no asisten a las reuniones o realizan intervenciones vacías y pobres.

Sobre el último aspecto se considera que el papel del juez en su calidad de director del proceso y encargado de la verificación en la etapa de ejecución es fundamental para lograr un proceso de seguimiento exitoso y efectivo. Su proceder activo o pasivo influenciará inevitablemente la posibilidad de transformación y ampliación de los mecanismos existentes. Al respecto, se encuentra que la normatividad vigente abre la puerta para la incorporación, por parte del juez, de nuevas herramientas que le permitan asegurar la efectividad de sus decisiones.

Así, un marco legislativo amplio, aunado a un juez propositivo, ha permitido la exploración de figuras nuevas que fundamentan la verificación en indicadores de cumplimiento, que permiten una comprensión más completa del grado de cumplimiento de las órdenes proferidas y que inspiran la creación futura de mejores herramientas.

Las acciones populares son, ante todo, una herramienta poderosa en la protección de los derechos colectivos. Sin embargo, la garantía efectiva de los mismos dependerá en la práctica de la creación y fortalecimiento de los mecanismos de seguimiento existentes. El panorama es en general conflictivo, pero esperanzador. Las herramientas están a disposición del juez y del Ministerio Público para lograr ese objetivo, existe suficiente amplitud en los poderes otorgados y en las posibilidades a futuro, sin embargo, el mejoramiento en el cumplimiento de las decisiones dependerá de que se tenga siempre como norte la primacía de los derechos humanos y de que los responsables se empoderen del importante rol que les corresponde.

\section{REFERENCIAS BIBLIOGRÁFICAS}

Acción de Tutela, T-252/14 (Corte Constitucional 23 de 04 de 2014).

Acción Popular, EXP. No 88-001-23-33-000-2014-00058-00 (Tribunal Contencioso Administrativo de San Andrés, Providencia y Santa Catalina 01 de 03 de 2016).

Acción Popular, Expediente No. 11001-33-31-040-2007-00158-00 (Juzgado 40 Administrativo de Oralidad del Circuito de Bogotá, Sección Cuarta 2007). 
Acción Popular, No. 007 (Sección Tercera 02 de12 de 1999).

Acción Popular, RAD. No 250002315000200302481-01 (Consejo de Estado, Sala de lo Contencioso Administrativo, Sección Primera, 10 de 12 de 2008).

Acción Popular, Rad. No. 4400-23-31-000-2005-00328-01 (Tribunal Contencioso Administrativo de La Guajira 2005).

Acta Comité de Verificación, Acta número 012-16 (Tribunal Contencioso Administrativo del Archipiélago, 13/07/16).

Acta de Reunión de Comité de Seguimiento en Acción Popular, Rad. No. 4400-23-31-000-2005-00328-00 (Tribunal Contencioso Administrativo de La Guajira, 06/08/10).

Acta No. 2 de reunión de Comité de Seguimiento en Acción Popular, Rad. No. 4400-23-31-000-2005-00328-00 (Tribunal Contencioso Administrativo de La Guajira 22/11/10).

Bravo, P. V. (2013). ¿Se han transformado las acciones populares con ocasión de los cambios normativos y jurisprudenciales ocurridos en el periodo 2006-2012? (Tesis de maestría). U. d. Rosario, Ed. Bogotá D.C:

Concepto del 13 de agosto de 2003, Radicación número 1519.13 (Sala de Consulta y Servicio Civil 13/08/03).

Constitución Política de Colombia. (1991).

Decreto 2591. Por el cual se reglamenta la acción de tutela consagrada en el artículo 86 de la Constitución Política. (1991). Colombia.

Defensoría del Pueblo. (2003-2016). Defensoría del Pueblo Colombia. Recuperado el 01 de 2017, de www.defensoria.gov.co

Defensoría del Pueblo. (2007). Cartilla de Acciones Populares y de Grupo. Colombia.

Diligencia de Audiencia para Verificación, Rad. No.25000231500 0200302481 (Consejo de Estado, Sala de lo Contencioso Administrativo, Sección Primera 23, 02/12). 
Diligencia de Audiencia para Verificación, Rad. No.25000231500 0200302481 (Consejo de Estado, Sala de lo Contencioso Administrativo, Sección Primera 13, 07/12).

Diligencia de Audiencia para Verificación, Rad. No.25000231500 0200302481 (Consejo de Estado, Sala de lo Contencioso Administrativo, Sección Primera 21, 08/12).

Diligencia de Audiencia para Verificación, Rad. No.25000231500 0200302481 (Consejo de Estado, Sala de lo Contencioso Administrativo, Sección Primera 25, 06/13).

Diligencia de Audiencia para Verificación, Rad. No.25000231500 0200302481 (Consejo de Estado, Sala de lo Contencioso Administrativo, Sección Primera 06, 05/14).

Fernanda Benavides Burbano, B. L. (2006). El pacto de cumplimiento y la garantía de los derechos colectivos. Bogotá D.C, Colombia: Editorial Universidad del Rosario.

Gamboa, J. O. (2010). Acciones Populares y medidas cautelares en defensa de los derechos colectivos. Un paso en la consolidación del Estado Social de Derecho. Bogotá D.C, Colombia: Editorial Universidad Externado de Colombia.

Kennedy, D. (1999). Libertad y restricción en la decisión judicial, El debate con la Teoría Crítica del Derecho (CLS). Bogotá D.C, Colombia: Siglo del Hombre Editores.

Observatorio Regional Ambiental y de Desarrollo Sostenible del Río Bogotá y Consejo Estratégico de la Cuenca Hidrográfica del Río Bogotá. (s.f.). Recuperado el 10 de 2016, de Información Ambiental para la Gestión Integral de la Cuenca Hídrica del Río Bogotá: www.orarbo.gov.co

Sala Especial de Seguimiento a la Sentencia T-025 de 2004 y sus autos de cumplimiento, Auto 099 de 2013 (Corte Constitucional 21/05/13).

Salazar, L. F. (2010). La acción popular: herramienta del Ministerio Público en la defensa del medio ambiente. Bogotá D.C, Colombia: Pontificia Universidad Javeriana. 
Sentencia de Tutela, T-443/13 (11 de 07 de 2013).

Sentencia, Rad: 15001-23-31-000-2004-00966-02 (AP) (Sala de lo Contencioso Administrativo, Sección Tercera 15/12/11). 